\title{
Revelation of a functional dependence of the sum of two uniaxial strengths/hardness on elastic work/total work of indentation
}

\author{
Dejun Ma \\ Department of Mechanical Engineering, The Academy of Armored Forces Engineering, \\ Beijing 100072, People's Republic of China \\ Taihua Zhang \\ State Key Laboratory of Nonlinear Mechanics (LNM), Institute of Mechanics, \\ Chinese Academy of Sciences, Beijing 100080, People's Republic of China \\ Chung Wo Ong ${ }^{\text {a) }}$ \\ Department of Applied Physics and Materials Research Center, The Hong Kong Polytechnic \\ University, Hung Hom, Kowloon, Hong Kong, People's Republic of China
}

(Received 3 August 2005; accepted 19 December 2005)

Dimensional and finite element analyses were used to analyze the relationship between the mechanical properties and instrumented indentation response of materials. Results revealed the existence of a functional dependence of (engineering yield strength $\sigma_{\mathrm{E}, \mathrm{y}}+$ engineering tensile strength $\left.\sigma_{\mathrm{E}, \mathrm{b}}\right) /$ Oliver \& Pharr hardness on the ratio of reversible elastic work to total work obtained from an indentation test. The relationship links up the Oliver \& Pharr hardness with the material strengths, although the Oliver \& Pharr hardness may deviate from the true hardness when sinking in or piling up occurs. The functional relationship can further be used to estimate the sum $\sigma_{\mathrm{E}, \mathrm{y}}+\sigma_{\mathrm{E}, \mathrm{b}}$ according to the data of an instrumented indentation test. The $\sigma_{\mathrm{E}, \mathrm{y}}+\sigma_{\mathrm{E}, \mathrm{b}}$ value better reflects the strength of a material compared to the hardness value alone. The method was shown to be effective when applied to aluminum alloys. The relationship can further be used to estimate the fatigue limits, which are usually obtained from macroscopic fatigue tests in different modes.

\section{INTRODUCTION}

There has been a long-lasting attempt to correlate the results obtained from indentation test with the fundamental mechanical properties of a material. More than 50 years ago, Tabor ${ }^{1}$ first reported that the hardness $H$ of some metals obtained from indentation tests by using a conical indenter was $\sim 3$ times a "representative yield stress $\left(Y_{\mathrm{o}}\right)$," where $Y_{\mathrm{o}}$ was the true yield stress at a 0.08 true yield strain. This finding linked up the hardness with the standard material properties obtained from a uniaxial tensile/compressive test. Along with the development of depth-sensing indentation technique in the past decades, Tabor's conjecture was reexamined over a larger variety of materials. Cheng and $\mathrm{Cheng}^{2}$ further introduced dimensional and finite element analyses (FEA) for conical indentation, and pointed out that when the ratio of yield

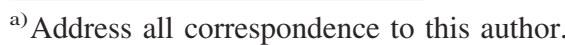
e-mail: apacwong@inet.polyu.edu.hk DOI: $10.1557 / J M R .2006 .0111$
}

strength to Young's modulus increased from 0.0002 to 0.1 , the ratio $H / Y_{\mathrm{o}}$ would drop from about 2.8 to 1.7. Dao et al. also reported a similar trend, ${ }^{3}$ leading to the conclusion that there was no simple proportional relationship between hardness and yield stress.

Another line of thought is to correlate the whole set of load-displacement data, rather than hardness value alone, with a group of fundamental material elastoplastic properties, such as Young's modulus E, yield strength, Poisson's ratio $v$, and stain-hardening exponent $n{ }^{3-5}$ However, Cheng and Cheng, ${ }^{6}$ Capehard and Cheng, ${ }^{7}$ and Tho et al. ${ }^{8}$ pointed out that uniquely determining a set of the material parameters from a single set of load-displacement curves was unlikely. Therefore, more recently, a new approach has been developed: using two conical indenters of different half included angles to produce independent load-displacement curves for deriving material properties like yield stress and hardening coefficient etc. ${ }^{9-12}$ In fact, more work is still required to examine the effectiveness and possible error of the method. 


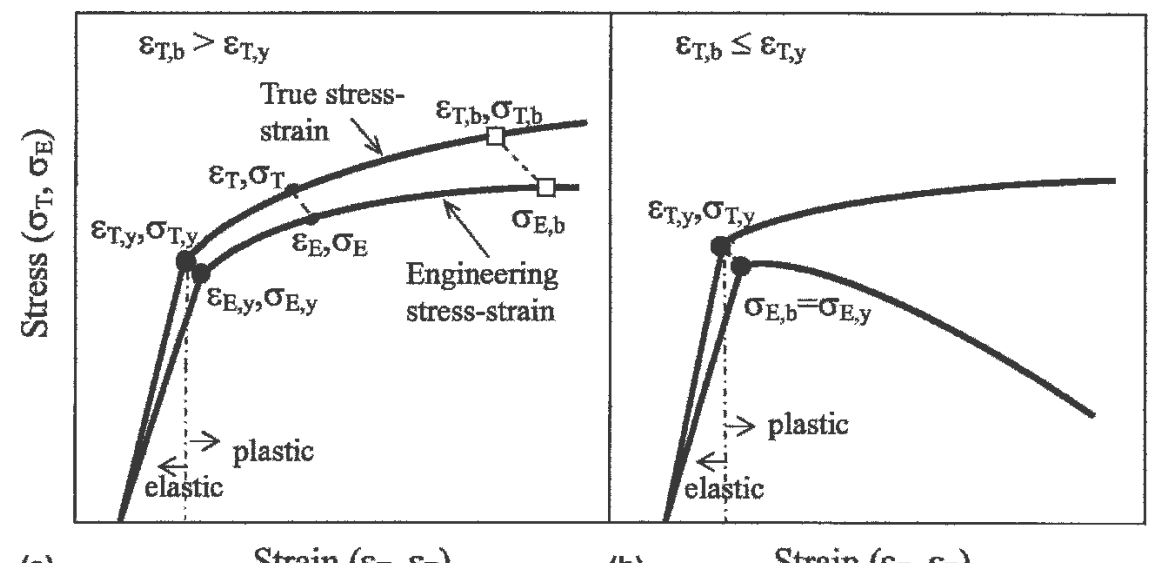

(a)

Strain $\left(\varepsilon_{\mathrm{T}}, \varepsilon_{\mathrm{E}}\right)$

(b)

Strain $\left(\varepsilon_{\mathrm{T}}, \varepsilon_{\mathrm{E}}\right)$

FIG. 1. Schematic diagrams showing the true and engineering stress-strain curves and the stress and strain quantities related to the study for the cases of (a) $\epsilon_{\mathrm{T}, \mathrm{b}}>\epsilon_{\mathrm{T}, \mathrm{y}}$ and (b) $\epsilon_{\mathrm{T}, \mathrm{b}} \leqslant \epsilon_{\mathrm{T}, \mathrm{y}}$.

In this paper, we report the results of a different approach. The method involves the symbols as shown in Fig. 1(a), where $\sigma_{\mathrm{T}}$ and $\epsilon_{\mathrm{T}}$ are the true stress and strain, $\sigma_{\mathrm{E}}$ and $\epsilon_{\mathrm{E}}$ the engineering stress and strain, and $\sigma_{\mathrm{T}, \mathrm{y}}, \epsilon_{\mathrm{T}, \mathrm{y}}$, $\sigma_{\mathrm{E}, \mathrm{y}}$, and $\epsilon_{\mathrm{E}, \mathrm{y}}$ the corresponding values at the yield point. The true stress and strain at the maximum engineering stress $\sigma_{\mathrm{E}, \mathrm{b}}$ (tensile strength) are $\sigma_{\mathrm{T}, \mathrm{b}}$ and $\epsilon_{\mathrm{T}, \mathrm{b}}$. Based on dimensional and finite element analyses, the proposed method leads to the establishment of a functional dependence of $\left(\sigma_{\mathrm{E}, \mathrm{y}}+\sigma_{\mathrm{E}, \mathrm{b}}\right) /$ Oliver \& Pharr hardness on the reversible elastic work/total work ratio deduced from a set of load-unload curves. The method involves only the use of one conical indenter. The relationship links up the Oliver \& Pharr hardness with the material strengths. It is also useful in estimating the sum $\sigma_{\mathrm{E}, \mathrm{y}}+\sigma_{\mathrm{E}, \mathrm{b}}$, where $\sigma_{\mathrm{E}, \mathrm{y}}$ and $\sigma_{\mathrm{E}, \mathrm{b}}$ are usually obtained from a standard uniaxial tensile test. This method is shown to be effective in estimating $\sigma_{\mathrm{E}, \mathrm{y}}+\sigma_{\mathrm{E}, \mathrm{b}}$ of aluminum alloys according to the published experimental results. The possibility of using the relationship in estimating the fatigue limits of materials is also proposed and discussed.

\section{FUNCTIONAL DEPENDENCE OF $\sigma_{E, Y}$ AND $\sigma_{E, B}$ ON FUNDAMENTAL MATERIAL PARAMETERS}

\section{A. Functional dependence of $\sigma_{\mathrm{E}, \mathrm{y}}$ on fundamental material parameters}

The uniaxial true stress-strain behavior of a solid to be analyzed is assumed to have a line with a slope of $E$ in the elastic region, plus a curve obeying Hollomon's power law of hardening in the plastic region [Fig. 1(a)]. The function form is

$$
\sigma_{\mathrm{T}}=\left\{\begin{array}{ll}
E \epsilon_{\mathrm{T}}, & \epsilon_{\mathrm{T}} \leqslant \epsilon_{\mathrm{T}, \mathrm{y}} \\
\sigma_{\mathrm{T}, \mathrm{y}}\left(\epsilon_{\mathrm{T}} / \epsilon_{\mathrm{T}, \mathrm{y}}\right)^{n}, & \epsilon_{\mathrm{T}}>\epsilon_{\mathrm{T}, \mathrm{y}}
\end{array},\right.
$$

where $\epsilon_{\mathrm{T}, \mathrm{y}}=\sigma_{\mathrm{T}, \mathrm{y}} / E$. In Appendix A, it is found that $\sigma_{\mathrm{E}, \mathrm{y}}$ can be expressed as a function of the fundamental material properties $\sigma_{\mathrm{T}, \mathrm{y}}\left(\right.$ or $\left.\epsilon_{\mathrm{T}, \mathrm{y}}\right), E$ and $\nu$.

$$
\sigma_{\mathrm{E}, \mathrm{y}}=\sigma_{\mathrm{T}, \mathrm{y}} / \exp \left(2 \nu \epsilon_{\mathrm{T}, \mathrm{y}}\right)=\sigma_{\mathrm{T}, \mathrm{y}} / \exp \left(2 \nu \sigma_{\mathrm{T}, \mathrm{y}} / E\right) .
$$

\section{B. Functional dependence of $\sigma_{E, b}$ on fundamental material properties}

We derive the functional dependence of $\sigma_{\mathrm{E}, \mathrm{b}}$ on the fundamental material properties of the indented material for two cases. Case 1 is for the condition of $\epsilon_{\mathrm{T}, \mathrm{b}} \leqslant \epsilon_{\mathrm{T}, \mathrm{y}}$. Figure 1(b) provides a primary sketch for this case. When the engineering stress is increased to $\sigma_{\mathrm{E}, \mathrm{y}}$, the specimen reaches the yield point. For further increase in engineering strain, the corresponding engineering stress decreases subsequently. This means that the engineering yield stress $\sigma_{\mathrm{E}, \mathrm{y}}$ is the maximum in the engineering stressstrain curve, and hence is equal to $\sigma_{\mathrm{E}, \mathrm{b}}$, i.e., $\sigma_{\mathrm{E}, \mathrm{b}}=$ $\sigma_{\mathrm{E}, \mathrm{y}}=\sigma_{\mathrm{T}, \mathrm{y}} / \exp \left(2 \nu \epsilon_{\mathrm{T}, \mathrm{y}}\right)$.

Case 2 is for the condition of $\epsilon_{\mathrm{T}, \mathrm{b}}>\epsilon_{\mathrm{T}, \mathrm{y}}$ as shown in Fig. 1(a). Appendix B shows that the true strain $\epsilon_{T, b}$ at maximum engineering stress $\sigma_{\mathrm{E}, \mathrm{b}}$ is

$$
\epsilon_{\mathrm{T}, \mathrm{b}}=n\left[1+(1-2 \nu) \epsilon_{\mathrm{T}, \mathrm{y}}^{1-n} \epsilon_{\mathrm{T}, \mathrm{b}}^{n}\right] .
$$

Conceptually, $\epsilon_{\mathrm{T}, \mathrm{b}}$ can be regarded as a function of $n, v$, and $\epsilon_{\mathrm{T}, \mathrm{y}}$, because when these three parameters are known, $\epsilon_{\mathrm{T}, \mathrm{b}}$ can normally be deduced by using Newton's method. Appendix B also shows that:

$$
\begin{aligned}
\sigma_{\mathrm{E}, \mathrm{b}} & =\sigma_{\mathrm{T}, \mathrm{b}} / \exp \left[\epsilon_{\mathrm{T}, \mathrm{b}}+(2 v-1) \epsilon_{\mathrm{T}, \mathrm{y}}^{1-n} \epsilon_{\mathrm{T}, \mathrm{b}}^{n}\right] \\
& =\sigma_{\mathrm{T}, \mathrm{y}}\left(\epsilon_{\mathrm{T}, \mathrm{b}} / \epsilon_{\mathrm{T}, \mathrm{y}}\right)^{n} / \exp \left[\epsilon_{\mathrm{T}, \mathrm{b}}+(2 v-1) \epsilon_{\mathrm{T}, \mathrm{y}}^{1-n} \epsilon_{\mathrm{T}, \mathrm{b}}^{n}\right],
\end{aligned}
$$

where $\sigma_{\mathrm{T}, \mathrm{b}}=\sigma_{\mathrm{T}, \mathrm{y}}\left(\epsilon_{\mathrm{T}, \mathrm{b}} / \epsilon_{\mathrm{T}, \mathrm{y}}\right)^{n}$ is applied. Summarizing the results of the two cases: 


$$
\begin{aligned}
& \sigma_{\mathrm{E}, \mathrm{b}}= \\
& \begin{cases}\sigma_{\mathrm{E}, \mathrm{y}}=\sigma_{\mathrm{T}, \mathrm{y}} / \exp \left(2 \nu \epsilon_{\mathrm{T}, \mathrm{y}}\right) & , \epsilon_{\mathrm{T}, \mathrm{b}} \leqslant \epsilon_{\mathrm{T}, \mathrm{y}} \\
\frac{\sigma_{\mathrm{T}, \mathrm{y}}\left(\epsilon_{\mathrm{T}, \mathrm{b}} / \epsilon_{\mathrm{T}, \mathrm{y}}\right)^{n}}{\exp \left[\epsilon_{\mathrm{T}, \mathrm{b}}+(2 \nu-1) \epsilon_{\mathrm{T}, \mathrm{y}}^{1-n} \epsilon_{\mathrm{T}, \mathrm{b}}^{n}\right]} & , \epsilon_{\mathrm{T}, \mathrm{b}}>\epsilon_{\mathrm{T}, \mathrm{y}}\end{cases}
\end{aligned}
$$

indicating that in any case $\sigma_{\mathrm{E}, \mathrm{b}}$ is a function of fundamental material properties $\sigma_{\mathrm{T}, \mathrm{y}}\left(\right.$ or $\left.\epsilon_{\mathrm{T}, \mathrm{y}}\right), E, \nu$, and $n$.

Combining Eqs. (2) and (5), one obtains an important corollary that the sum $\sigma_{\mathrm{E}, \mathrm{y}}+\sigma_{\mathrm{E}, \mathrm{b}}$ is a function of the fundamental material properties. This conclusion can be expressed with an implicit relationship like

$$
\sigma_{\mathrm{E}, \mathrm{y}}+\sigma_{\mathrm{E}, \mathrm{b}}=f\left(\sigma_{\mathrm{T}, \mathrm{y}}, E, \nu, n\right),
$$

or alternatively

$$
\sigma_{\mathrm{T}, \mathrm{y}}=g\left[\left(\sigma_{\mathrm{E}, \mathrm{y}}+\sigma_{\mathrm{E}, \mathrm{b}}\right), E, \nu, n\right) .
$$

\section{DIMENSIONAL AND FINITE ELEMENT ANALYSES OF HYPOTHETICAL INDENTATION TESTS}

We use the Oliver \& Pharr hardness in this study, which is defined as ${ }^{11-13}$ :

$$
H=P_{\mathrm{m}} / A\left(h_{\mathrm{cm}}\right),
$$

where $h_{\mathrm{cm}}$ and $A\left(h_{\mathrm{cm}}\right)$ are the maximum contact depth and the related projected contact area measured at the peak load $P_{\mathrm{m}} \cdot h_{\mathrm{cm}}$ is defined according to the formula

$$
h_{\mathrm{cm}}=h_{\mathrm{m}}-0.75 P_{\mathrm{m}} / S_{\mathrm{u}},
$$

where $h_{\mathrm{m}}$ and $S_{u}$ are the maximum displacement and unloading slope at $P_{\mathrm{m}}$. The indenter is considered to be an elastic body. The contact interface between the indenter and the indented material is assumed to be frictionless. $H$ is regarded to be the indentation response, and is a function of the elasto-plastic properties $E, \nu, \sigma_{\mathrm{T}, \mathrm{y}}$, and $n$ of the indented material; the elastic properties $E_{\mathrm{i}}$ and $\nu_{\mathrm{i}}$ of the indenter; and the maximum indentation depth $h_{m}$. It can be expressed in an implicit form of

$$
H=F_{\mathrm{H}}\left(E, v, \sigma_{\mathrm{T}, \mathrm{y}}, n, E_{\mathrm{i}}, \nu_{\mathrm{i}}, h_{\mathrm{m}}\right) .
$$

By substituting Eq. (7) into Eq. (10), $H$ can be expressed as

$$
\begin{aligned}
H & =F_{\mathrm{H}}\left(E, v, \mathrm{~g}\left[\left(\sigma_{\mathrm{E}, \mathrm{y}}+\sigma_{\mathrm{E}, \mathrm{b}}\right), E, v, n\right], n, E_{\mathrm{i}}, \nu_{\mathrm{i}}, h_{\mathrm{m}}\right) \\
& =\Psi_{\mathrm{H}}\left(E, v,\left(\sigma_{\mathrm{E}, \mathrm{y}}+\sigma_{\mathrm{E}, \mathrm{b}}\right), n, E_{\mathrm{i}}, \nu_{\mathrm{i}}, h_{\mathrm{m}}\right) .
\end{aligned}
$$

Furthermore, according to Dao et al.'s analysis on sharp indentation, ${ }^{3}$ the function can be simplified by introducing a reduced Young's modulus $E_{r}=1 /\left[\left(1-v^{2}\right) / E+\right.$ $\left.\left(1-\mathrm{v}_{\mathrm{i}}{ }^{2}\right) / E_{\mathrm{i}}\right]$, which combines the overall elasticity effects of the indenter and the indented material. Then, Eq. (11) becomes

$$
H=\Phi_{\mathrm{H}}\left[\left(\sigma_{\mathrm{E}, \mathrm{y}}+\sigma_{\mathrm{E}, \mathrm{b}}\right), n, E_{\mathrm{r}}, h_{\mathrm{m}}\right] .
$$

By applying the $\Pi$ theorem of dimensional analysis, Eq. (12) can be transformed into the following dimensionless formula

$$
H / E_{\mathrm{r}}=\Gamma_{\mathrm{H}}\left[\left(\sigma_{\mathrm{E}, \mathrm{y}}+\sigma_{\mathrm{E}, \mathrm{b}}\right) / E_{\mathrm{r}}, n\right] .
$$

Similar analysis can be conducted for the ratio of reversible elastic work to total work $W_{\mathrm{e}} / W$. Analogous to Eq. (10), let us write $W_{\mathrm{e}} / W=F_{\mathrm{W}}\left(E, v, \sigma_{\mathrm{T}, \mathrm{y}}, n, E_{\mathrm{i}}, \nu_{\mathrm{i}}, h_{\mathrm{m}}\right)$, where $W_{\mathrm{e}}$ and $W$ are the areas under the unloading and loading curves respectively. An expression analogous to Eq. (13) is obtained, namely:

$$
W_{\mathrm{e}} / W=\Gamma_{\mathrm{W}}\left[\left(\sigma_{\mathrm{E}, \mathrm{y}}+\sigma_{\mathrm{E}, \mathrm{b}}\right) / E_{\mathrm{r}}, n\right],
$$

or

$$
\left(\sigma_{\mathrm{E}, \mathrm{y}}+\sigma_{\mathrm{E}, \mathrm{b}}\right) / E_{\mathrm{r}}=\Gamma_{\mathrm{S}}\left(W_{\mathrm{e}} / W, n\right) .
$$

Substituting Eq. (15) into Eq. (13) to eliminate $\sigma_{\mathrm{E}, \mathrm{y}}+$ $\sigma_{\mathrm{E}, \mathrm{b}}$, we obtain

$$
H / E_{\mathrm{r}}=\Gamma_{\mathrm{H}}\left[\Gamma_{\mathrm{S}}\left(W_{\mathrm{e}} / W, n\right), n\right]=\Gamma_{\mathrm{HS}}\left(W_{\mathrm{e}} / W, n\right)
$$

Further dividing Eq. (15) by Eq. (16), we obtain

$$
\begin{gathered}
\left(\sigma_{\mathrm{E}, \mathrm{y}}+\sigma_{\mathrm{E}, \mathrm{b}}\right) / H=\Gamma_{\mathrm{S}}\left(W_{\mathrm{e}} / W, n\right) / \Gamma_{\mathrm{HS}}\left(W_{\mathrm{e}} / W, n\right) \\
=\Gamma_{\mathrm{SHW}}\left(W_{\mathrm{e}} / W, n\right) .
\end{gathered}
$$

In this study, we applied FEA to simulate the indentation tests to establish the explicit form of Eq. (17) for practical use. The commercial finite element code ABAQUS ${ }^{14}$ was used for the computation processes because of its excellent capability for handling problems of strong nonlinearity and large displacement. The analysis was performed in the framework of continuum. The indenter was assumed to be a cone with a half-included angle of $70.3^{\circ}$ and thus was geometrically equivalent to an ideal Berkovich indenter. The indented material was assumed to be isotropic and rate-independent. It obeyed the Von Mises yield criterion and pure isotropic hardening rule. The details of meshing are described elsewhere. ${ }^{16,17}$ Four-node axisymmetric element type was used, with a size small enough to give more than 30 nodes around the point of contact. A sensitivity study was performed by reducing the element size by half. Results showed that the calculated peak load was not changed by more than $0.6 \%$, confirming that the selected mesh size was fine enough for modeling the hypothetical conical indentation made on a semi-infinite solid.

Considering that $\left(\sigma_{\mathrm{E}, \mathrm{y}}+\sigma_{\mathrm{E}, \mathrm{b}}\right) / H$ and $W_{\mathrm{e}} / W$ in Eq. (17) are independent on $E_{\mathrm{r}}$ and $h_{\mathrm{m}}$, we may keep $E_{r}$ and $h_{m}$ unchanged by assigning fixed values to all the elastic properties $\left(E, v, E_{\mathrm{i}}, v_{\mathrm{i}}\right)$ and the maximum indentation depth $h_{\mathrm{m}}$. In fact, the indenter is assumed to be rigid, so 
that $E_{\mathrm{i}}$ and $\nu_{\mathrm{i}}$ can be removed for further simplicity. $E, \nu$, and $h_{m}$ were fixed at $70 \mathrm{GPa}, 0.3$, and $1 \mu \mathrm{m}$ respectively, and hence $E_{\mathrm{r}}$ was calculated to be $E /\left(1-v^{2}\right)=70 \mathrm{GPa} /$ $\left(1-0.3^{2}\right)=76.923 \mathrm{GPa}$. Fifty-six combinations of $\sigma_{\mathrm{T}, \mathrm{y}}$ and $n$ were selected, with their values in the ranges of $0.035-17.5 \mathrm{GPa}$ and $0-0.45$ respectively. For each combination, the corresponding value of $\sigma_{\mathrm{E}, \mathrm{y}}+\sigma_{\mathrm{E}, \mathrm{b}}$ was calculated from Eqs. (2) and (5) as shown in Table I. FEA was applied to simulate an indentation to produce the load-unload curves, from which the value of $W_{\mathrm{e}} / W$ was calculated, and the value of $H$ was derived with the use of Eqs. (8) and (9). Finally, the value of $\left(\sigma_{\mathrm{E}, \mathrm{y}}+\right.$ $\left.\sigma_{\mathrm{E}, \mathrm{b}}\right) / H$ is determined and plotted against $W_{\mathrm{e}} / W$ in Fig. 2 with $n$ as a parameter. More interpolated data were produced based on the matrix as shown in Table I, with the locations selected at $1 / 3$ and $2 / 3$ between every two adjacent $n$ values and every two adjacent $\sigma_{\mathrm{T}, \mathrm{y}}$ values. This created 344 more combinations. Starting from a certain $n$ (i.e., one of $0,0.15,0.3$ and 0.45 ), the interpolated vales of $\left(\sigma_{\mathrm{E}, \mathrm{y}}+\sigma_{\mathrm{E}, \mathrm{b}}\right) / H$ and $W_{\mathrm{e}} / W$ were obtained from the FEA results evaluated at four adjacent $\sigma_{\mathrm{T}, \mathrm{y}}$ values as listed in Table I, with the use of a third-order polynomial. Then, for a certain $\sigma_{\mathrm{T}, \mathrm{y}}$, more interpolated values of $\left(\sigma_{\mathrm{E}, \mathrm{y}}+\right.$ $\left.\sigma_{\mathrm{E}, \mathrm{b}}\right) / H$ and $W_{\mathrm{e}} / W$ were derived from the FEA results evaluated at $n=0,0.15,0.3$ and 0.45 , with the use of a third-order polynomial. All the FEA data and interpolated data are plotted in Fig. 2. It is found that $\left(\sigma_{\mathrm{E}, \mathrm{y}}+\right.$ $\left.\sigma_{\mathrm{E}, \mathrm{b}}\right) / H$ and $W_{\mathrm{e}} / W$ are correlated with a functional relationship, which is almost irrespective of the variation of $n$ in a broad range. Hence, the value of $\left(\sigma_{\mathrm{E}, \mathrm{y}}+\sigma_{\mathrm{E}, \mathrm{b}}\right) / H$ and $W_{\mathrm{e}} / W$ can be uniquely determined by the ratio of $W_{\mathrm{e}} / W$.

In our previous work, ${ }^{15}$ it was demonstrated that for $W_{\mathrm{e}} / W<0.25$, the Oliver \& Pharr hardness may be very different from the real hardness ( $\equiv$ indentation load/real projected contact area). In addition, the relationships

TABLE I. Values of $\sigma_{\mathrm{T}, \mathrm{y}} n$, and $\left(\sigma_{\mathrm{E}, \mathrm{y}}+\sigma_{\mathrm{E}, \mathrm{b}}\right)$ used in numerical analysis (stresses in $\mathrm{GPa}$ ).

\begin{tabular}{rrrrr}
\hline \hline & \multicolumn{4}{c}{$\sigma_{\mathrm{E}, \mathrm{y}}+\sigma_{\mathrm{E}, \mathrm{b}}$} \\
\cline { 2 - 5 }$\sigma_{\mathrm{T}, \mathrm{y}}$ & $n=0$ & $n=0.15$ & $n=0.3$ & $n=0.45$ \\
\hline 0.035 & 0.070 & 0.106 & 0.212 & 0.514 \\
0.140 & 0.280 & 0.371 & 0.608 & 1.171 \\
0.350 & 0.698 & 0.852 & 1.241 & 2.066 \\
0.700 & 1.392 & 1.606 & 2.151 & 3.227 \\
1.400 & 2.767 & 3.031 & 3.763 & 5.128 \\
2.100 & 4.125 & 4.399 & 5.242 & 6.781 \\
2.800 & 5.467 & 5.730 & 6.644 & 8.301 \\
3.500 & 6.793 & 7.034 & 7.990 & 9.731 \\
4.550 & 8.752 & 8.949 & 9.935 & 11.756 \\
5.600 & 10.675 & 10.824 & 11.808 & 13.675 \\
7.000 & 13.185 & 13.274 & 14.218 & 16.107 \\
10.500 & 19.193 & 19.195 & 19.916 & 21.734 \\
14.000 & 24.834 & 24.834 & 25.253 & 26.889 \\
17.500 & 30.125 & 30.125 & 30.306 & 31.687 \\
\hline \hline
\end{tabular}

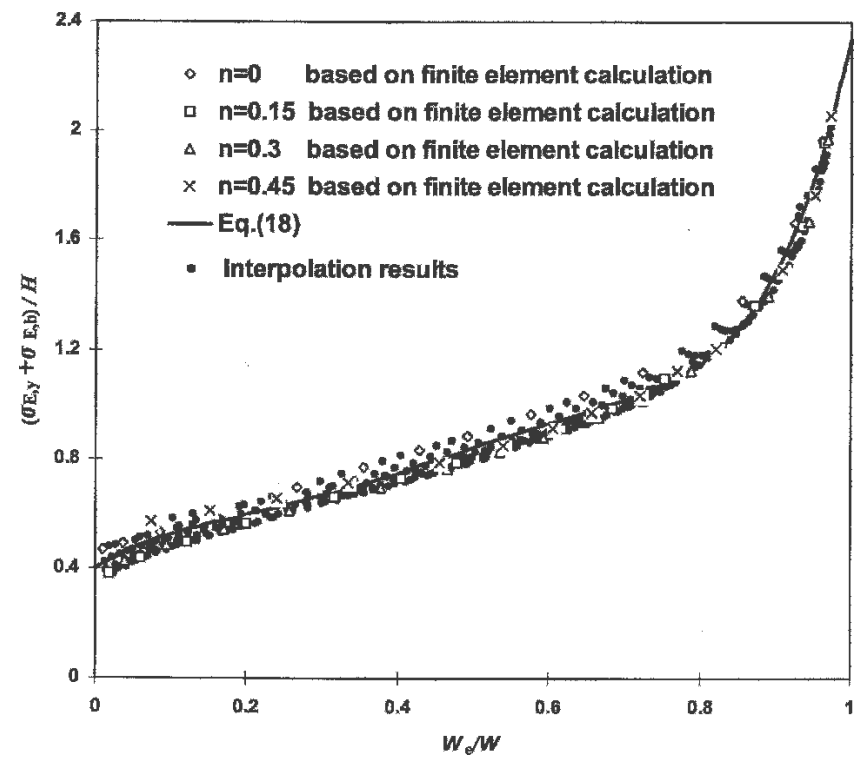

FIG. 2. Numerical values of $\left(\sigma_{\mathrm{E}, \mathrm{y}}+\sigma_{\mathrm{E}, \mathrm{b}}\right) / H=\Gamma_{\mathrm{SHW}}\left(W_{\mathrm{e}} / W, n\right)$ against $W_{\mathrm{e}} / W$ for different values of $n$ and the best fit to the data points expressed by Eq. (18).

established to correlate a true hardness with a representative yield are not applicable to the Oliver \& Pharr hardness. Therefore, one needs to ask what the real meaning of the Oliver \& Pharr hardness is, and how it is related to some fundamental properties like the intrinsic strengths of a material. The discovery of the above relationship gives possible answers by correlating the Oliver \& Pharr hardness with the sum of two characteristic strengths of a material.

Figure 2 also shows the best fit to the data points produced with a polynomial of

$$
\left(\sigma_{\mathrm{E}, \mathrm{y}}+\sigma_{\mathrm{E}, \mathrm{b}}\right) / H=f\left(W_{\mathrm{e}} / W\right)=a_{0}+\sum_{i=1}^{6} a_{i}\left(W_{\mathrm{e}} / W\right)^{i},
$$

where $a_{0}=0.40096, a_{1}=1.67585, a_{2}=-5.64402, a_{3}=$ 11.51201, $a_{4}=-0.15716, a_{5}=-21.09499$, and $a_{6}=$ 15.64194. Equation (18) can also be rewritten in the form of:

$$
\sigma_{\mathrm{E}, \mathrm{y}}+\sigma_{\mathrm{E}, \mathrm{b}}=H\left[f\left(W_{\mathrm{e}} / W\right)\right]=H\left[a_{0}+\sum_{i=1}^{6} a_{i}\left(W_{\mathrm{e}} / W\right)^{i}\right] .
$$

It is noted that $H$ in Eqs. (18) and (19) is not necessarily equal to the true hardness. For example, in the present study, we use Oliver \& Pharr's definition, but it does not always give the true hardness, since piling up or sinking in could occur to make the value of $h_{\mathrm{cm}}$ deduced from Eq. (9) different from the true contact depth. The setting of the value of $\epsilon$ induces further uncertainty, e.g., for a conical indenter Oliver and Pharr use $\epsilon=0.75$, but 
Sneddon uses $\epsilon=0.72$. In fact, the meaning of Eq. (18) or Eq. (19) is to provide a relationship between the sum of the strengths $\sigma_{\mathrm{E}, \mathrm{y}}+\sigma_{\mathrm{E}, \mathrm{b}}$ and Oliver \& Pharr's hardness through proper selection of the coefficients $a_{\mathrm{o}}$ to $a_{6}$, such that the value of $\sigma_{\mathrm{E}, \mathrm{y}}+\sigma_{\mathrm{E}, \mathrm{b}}$ can be deduced from the measured $H$ value. It is further assumed that the indentation is deep enough such that the indenter is considered to possess the ideal Berkovich geometry with a projected area of $A\left(h_{c m}\right)=24.5 h_{c m}{ }^{2}$. This is true in the present study since the experimental data are selected from indentation tests with maximum displacement $h_{\mathrm{m}}>$ $8 \mu \mathrm{m}$, which normally exceeds the bluntness of an indenter tip.

Denoting $\left(\sigma_{\mathrm{E}, \mathrm{y}}+\sigma_{\mathrm{E}, \mathrm{b}}\right)_{\mathrm{e}}$ as the result calculated from Eqs. (2) and (5) based on the model of the material properties, and $\left(\sigma_{\mathrm{E}, \mathrm{y}}+\sigma_{\mathrm{E}, \mathrm{b}}\right)_{\mathrm{f}}$ as the result obtained from Eq. (19) based on the finite element simulations, the ratio $\left(\sigma_{\mathrm{E}, \mathrm{y}}+\sigma_{\mathrm{E}, \mathrm{b}}\right)_{\mathrm{f}} /\left(\sigma_{\mathrm{E}, \mathrm{y}}+\sigma_{\mathrm{E}, \mathrm{b}}\right)_{\mathrm{e}}$ would reflect the consistency between the two values. Referring to Eqs. (17) and (19), $\left(\sigma_{\mathrm{E}, \mathrm{y}}+\sigma_{\mathrm{E}, \mathrm{b}}\right)_{\mathrm{f}} /\left(\sigma_{\mathrm{E}, \mathrm{y}}+\sigma_{\mathrm{E}, \mathrm{b}}\right)_{\mathrm{e}}$ would depend on $W_{\mathrm{e}} / W$ and $n$, namely, in implicit form:

$$
\begin{aligned}
& \left(\sigma_{\mathrm{E}, \mathrm{y}}+\sigma_{\mathrm{E}, \mathrm{b}}\right)_{\mathrm{f}} /\left(\sigma_{\mathrm{E}, \mathrm{y}}+\sigma_{\mathrm{E}, \mathrm{b}}\right)_{\mathrm{e}}= \\
& \left\{H\left[f\left(W_{\mathrm{e}} / W\right)\right]\right\} /\left\{H \Gamma_{\mathrm{SHW}}\left(W_{\mathrm{e}} / W, n\right)\right\}=\Gamma_{\mathrm{fe}}\left(W_{\mathrm{e}} / W, n\right) .
\end{aligned}
$$

The numerical results of $\Gamma_{\mathrm{fe}}\left(W_{\mathrm{e}} / W, n\right)$ are calculated and plotted in Fig. 3. A result of 1 refers to a perfect match, while most data points lie within a narrow band of $\pm 14 \%$.

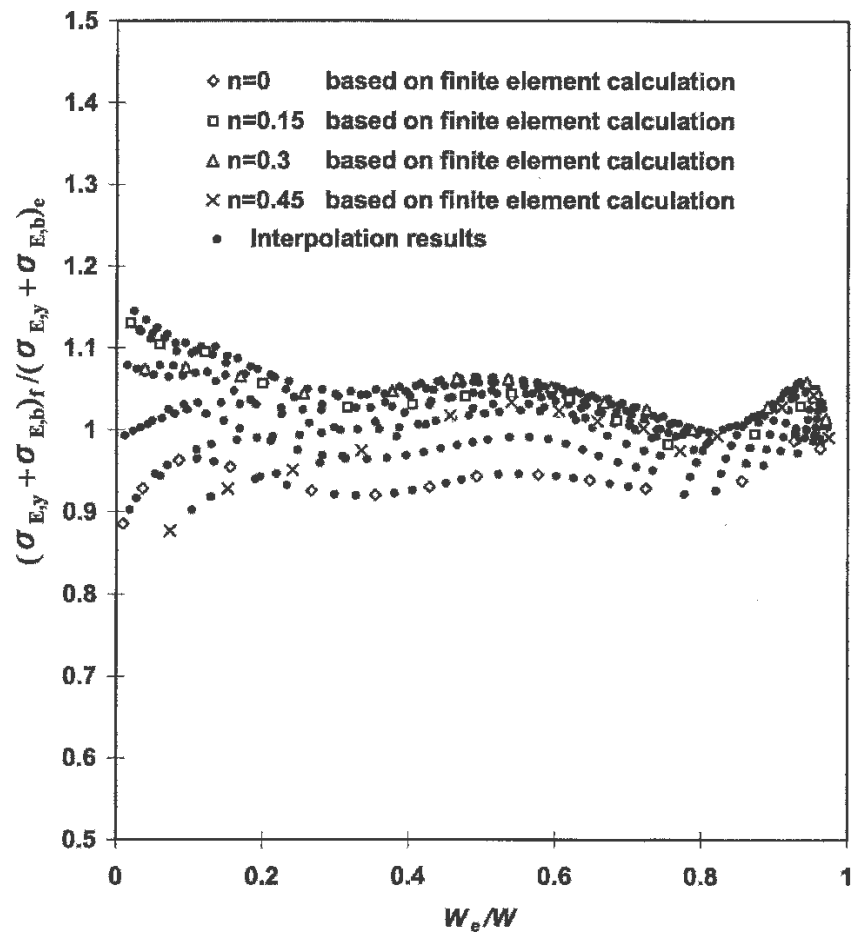

FIG. 3. Numerical values of $\left(\sigma_{\mathrm{E}, \mathrm{y}}+\sigma_{\mathrm{E}, \mathrm{b}}\right)_{\mathrm{f}} /\left(\sigma_{\mathrm{E}, \mathrm{y}}+\sigma_{\mathrm{E}, \mathrm{b}}\right)_{\mathrm{e}}=\Gamma_{\mathrm{fe}}\left(W_{\mathrm{e}} /\right.$ $W, n)$ against $W_{\mathrm{e}} / W$ for different values of $n$.

\section{EXPERIMENTAL EVALUATION OF THE THEORY}

We referred to some published data of stress-strain tests and indentation tests for two aluminum alloys 6061T6511 and 7075-T651 ${ }^{3}$ to examine the effectiveness of the theory. The parameters extracted from the stressstrain curves of uniaxial tests, and the sum of two strengths $\left(\sigma_{\mathrm{E}, \mathrm{y}}+\sigma_{\mathrm{E}, \mathrm{b}}\right)_{\mathrm{t}}$ obtained from uniaxial test with the use of Eqs. (2) and (5) are listed in Table II.

On the other hand, the results of the indentation tests are summarized in Table III. $h_{\mathrm{m}}$ is evaluated from the equation $h_{\mathrm{m}}=\left(P_{\mathrm{m}} / C\right)^{1 / 2}$, with $C$ being the loading curvature. The hardness $H$ is calculated from Eqs. (8) and (9). The sum of the two characteristic strengths is estimated from Eq. (19) and is denoted as $\left(\sigma_{\mathrm{E}, \mathrm{y}}+\sigma_{\mathrm{E}, \mathrm{b}}\right)_{\mathrm{i}}$ with the subscript $\mathrm{i}$ referring to a quantity deduced from an indentation test. The last column of Table III shows the relative error $\operatorname{Re}=\left[\left(\sigma_{\mathrm{E}, \mathrm{y}}+\sigma_{\mathrm{E}, \mathrm{b}}\right)_{\mathrm{i}}-\left(\sigma_{\mathrm{E}, \mathrm{y}}+\sigma_{\mathrm{E}, \mathrm{b}}\right)_{\mathrm{t}}\right] /$ $\left(\sigma_{\mathrm{E}, \mathrm{y}}+\sigma_{\mathrm{E}, \mathrm{b}}\right)_{\mathrm{i}}$. It is found that the values of $R_{\mathrm{e}}$ are located within a reasonably narrow range, supporting the effectiveness of the theory. Nevertheless, more experimental work should be done in the next stage to investigate a broader class of materials for further confirmation of the universal effectiveness of the method.

\section{APPLICATIONS OF THE FUNCTIONAL DEPENDENCE OF $\left(\sigma_{\mathrm{E}, \mathrm{y}}+\sigma_{\mathrm{E}, \mathrm{b}}\right) / H$ ON $W_{\mathrm{e}} / W$}

In this section, we propose two possible applications based on the functional dependence of $\left(\sigma_{\mathrm{E}, \mathrm{y}}+\sigma_{\mathrm{E}, \mathrm{b}}\right) / H$ on $W_{\mathrm{e}} / W$.

First, the relationship can be used to deduce the sum $\sigma_{\mathrm{E}, \mathrm{y}}+\sigma_{\mathrm{E}, \mathrm{b}}$ of a material from $H$ and $W_{\mathrm{e}} / W$ measured in an indentation test. This quantity reflects the fundamental property of a material since it is composed of two characteristic material strengths. However, in general, it does not vary coherently with hardness, although the latter is widely referred to as a material performance indicator in practice. This remark is clearly illustrated through Fig. 4, which shows how the ratio $\left[\left(\sigma_{\mathrm{E}, \mathrm{y}}+\sigma_{\mathrm{E}, \mathrm{b}}\right)_{1} /\left(\sigma_{\mathrm{E}, \mathrm{y}}+\sigma_{\mathrm{E}, \mathrm{b}}\right)_{2}\right] /$ $\left[H_{1} / H_{2}\right]$ varies with $\left(W_{\mathrm{e}} / W\right)_{1}$ and $\left(W_{\mathrm{e}} / W\right)_{2}$, with the subscripts " 1 " and " 2 " referring to the quantities of two materials respectively. According to Eq. (18), the ratio $\left[\left(\sigma_{\mathrm{E}, \mathrm{y}}+\sigma_{\mathrm{E}, \mathrm{b}}\right)_{1} /\left(\sigma_{\mathrm{E}, \mathrm{y}}+\sigma_{\mathrm{E}, \mathrm{b}}\right)_{2}\right] /\left[H_{1} / H_{2}\right]$ can be expressed as $f\left[\left(W_{\mathrm{e}} / W\right)_{1}\right] / f\left[\left(W_{\mathrm{e}} / W\right)_{2}\right]$, i.e., a function of $\left(W_{\mathrm{e}} / W\right)_{1}$ and

TABLE II. Experimental results of uniaxial tests for two aluminum alloys.

\begin{tabular}{lccccc}
\hline \hline Material & $E(\mathrm{GPa})$ & $v$ & $\sigma_{\mathrm{T}, \mathrm{y}}(\mathrm{MPa})$ & $n$ & $\begin{array}{c}\left(\sigma_{\mathrm{E}, \mathrm{y}}+\sigma_{\mathrm{E}, \mathrm{b}}\right)_{\mathrm{t}} \\
(\mathrm{MPa})\end{array}$ \\
\hline Al 6061 - T6511 & 66.8 & 0.33 & 284 & 0.08 & 615.4 \\
Al 7075-T651 & 70.1 & 0.33 & 500 & 0.122 & 1125.6 \\
\hline \hline
\end{tabular}


TABLE III. Experimental data of indentation tests for two aluminum alloys with a fixed $P_{\mathrm{m}}=3 \mathrm{~N}$.

\begin{tabular}{|c|c|c|c|c|c|c|c|c|}
\hline Material & $C(\mathrm{GPa})$ & $h_{\mathrm{m}}(\mu \mathrm{m})$ & $S_{\mathrm{u}}(\mathrm{N} / \mathrm{mm})$ & $H(\mathrm{GPa})$ & $W_{\mathrm{e}} / W$ & $f\left(W_{\mathrm{e}} / W\right)$ & $\left(\sigma_{\mathrm{E}, \mathrm{y}}+\sigma_{\mathrm{E}, \mathrm{b}}\right)_{\mathrm{i}}(\mathrm{MPa})$ & $\operatorname{Re}(\%)$ \\
\hline \multicolumn{9}{|c|}{ Al $6061-T 6511$} \\
\hline Test 1 & 27.4 & 10.46 & 4768 & 1.226 & 0.098 & 0.5216 & 639.8 & 3.8 \\
\hline Test 2 & 28.2 & 10.31 & 4800 & 1.263 & 0.095 & 0.5189 & 655.5 & 6.1 \\
\hline Test 3 & 27.2 & 10.50 & 4794 & 1.217 & 0.096 & 0.5198 & 632.4 & 2.7 \\
\hline Test 4 & 27.3 & 10.48 & 4671 & 1.224 & 0.111 & 0.5328 & 652.3 & 5.7 \\
\hline Test 5 & 27.0 & 10.54 & 4762 & 1.208 & 0.111 & 0.5328 & 643.6 & 4.4 \\
\hline Test 6 & 27.6 & 10.43 & 4491 & 1.243 & 0.109 & 0.5312 & 660.3 & 6.8 \\
\hline \multicolumn{9}{|c|}{ Al $7075-T 651$} \\
\hline Test 1 & 42.0 & 8.45 & 3665 & 1.993 & 0.167 & 0.5745 & 1145.2 & 1.7 \\
\hline Test 2 & 40.9 & 8.56 & 3658 & 1.938 & 0.162 & 0.5711 & 1106.6 & -1.7 \\
\hline Test 3 & 42.3 & 8.42 & 3654 & 2.010 & 0.168 & 0.5752 & 1156.0 & 2.6 \\
\hline Test 4 & 43.1 & 8.34 & 3744 & 2.043 & 0.164 & 0.5725 & 1169.5 & 3.8 \\
\hline Test 5 & 43.5 & 8.30 & 3789 & 2.060 & 0.161 & 0.5704 & 1174.7 & 4.2 \\
\hline Test 6 & 44.6 & 8.20 & 3706 & 2.123 & 0.169 & 0.5759 & 1222.6 & 7.9 \\
\hline
\end{tabular}

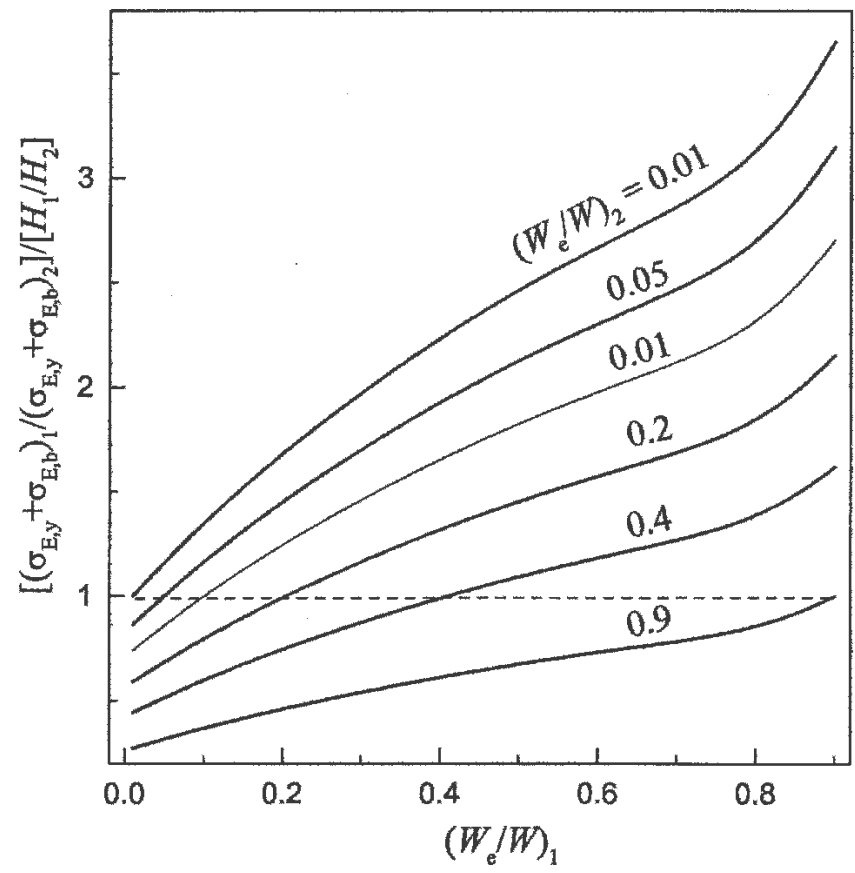

FIG. 4. Plot of the ratio $\left[\left(\sigma_{\mathrm{E}, \mathrm{y}}+\sigma_{\mathrm{E}, \mathrm{b}}\right)_{1} /\left(\sigma_{\mathrm{E}, \mathrm{y}}+\sigma_{\mathrm{E}, \mathrm{b}}\right)_{2}\right] /\left[H_{1} / H_{2}\right]$ as a function of $\left(W_{\mathrm{e}} / W\right)_{1}$ and $\left(W_{\mathrm{e}} / W\right)_{2}$, with the subscript " 1 " and " 2 " referring to the quantities of two materials.

$\left(W_{\mathrm{e}} / W\right)_{2}$. It is found that $\left[\left(\sigma_{\mathrm{E}, \mathrm{y}}+\sigma_{\mathrm{E}, \mathrm{b}}\right)_{1} /\left(\sigma_{\mathrm{E}, \mathrm{y}}+\sigma_{\mathrm{E}, \mathrm{b}}\right)_{2}\right] /$ $\left[H_{1} / H_{2}\right]$ could deviate significantly from 1 . As a numerical example, when $\left(W_{\mathrm{e}} / W\right)_{1}=0.6$ and $\left(W_{\mathrm{e}} / W\right)_{2}=0.05$, the values of $f\left[\left(W_{\mathrm{e}} / W\right)_{1}\right]$ and $f\left[\left(W_{\mathrm{e}} / W\right)_{2}\right]$ are 0.93 and 0.47 , respectively. This gives a ratio of $\left[\left(\sigma_{\mathrm{E}, \mathrm{y}}+\sigma_{\mathrm{E}, \mathrm{b}}\right)_{1} /\right.$ $\left.\left(\sigma_{\mathrm{E}, \mathrm{y}}+\sigma_{\mathrm{E}, \mathrm{b}}\right)_{2}\right] /\left[H_{1} / H_{2}\right]=1.97$, which is much greater than 1 . This verifies that comparison of hardnesses of two materials alone is not sufficient to reflect the difference between their strengths.

Second, the $\sigma_{\mathrm{E}, \mathrm{y}}+\sigma_{\mathrm{E}, \mathrm{b}}$ value deduced from the method can further be used to estimate the fatigue limits of some structure steels. At present, there are many empirical relationships established for correlating the fatigue limits with $\sigma_{\mathrm{E}, \mathrm{b}}$, but obviously the fatigue behavior should also be related to the yield stress $\sigma_{\mathrm{E}, \mathrm{y} \cdot}{ }^{18} \mathrm{~A}$ more reasonable approach is to link up the fatigue limits with some quantity containing both of them. According to Ref. 19, the fatigue limits measured with symmetric cycling stress in tensile-compressive mode, rotatingbending mode, and shearing stress mode are estimated to be

$$
\begin{aligned}
\sigma_{-1 l} & =0.23\left(\sigma_{\mathrm{E}, \mathrm{y}}+\sigma_{\mathrm{E}, \mathrm{b}}\right) \\
\sigma_{-1} & =0.27\left(\sigma_{\mathrm{E}, \mathrm{y}}+\sigma_{\mathrm{E}, \mathrm{b}}\right), \\
\tau_{-1} & =0.55 \sigma_{-1}=0.1485\left(\sigma_{\mathrm{E}, \mathrm{y}}+\sigma_{\mathrm{E}, \mathrm{b}}\right) .
\end{aligned}
$$

The corresponding quantities measured with pulsating cycling stress in the three modes are

$$
\begin{gathered}
\sigma_{\mathrm{o} l}=1.42 \sigma_{-1 l}=0.3266\left(\sigma_{\mathrm{E}, \mathrm{y}}+\sigma_{\mathrm{E}, \mathrm{b}}\right), \\
\sigma_{\mathrm{o}}=1.33 \sigma_{-1}=0.3591\left(\sigma_{\mathrm{E}, \mathrm{y}}+\sigma_{\mathrm{E}, \mathrm{b}}\right), \\
\tau_{\mathrm{o}}=1.50 \tau_{-1}=0.22275\left(\sigma_{\mathrm{E}, \mathrm{y}}+\sigma_{\mathrm{E}, \mathrm{b}}\right)
\end{gathered}
$$

Some experimental results cited from Ref. 20 for middle or low strength steels are shown in Table IV to show the effectiveness of Eqs. (21)-(26). In Table IV, $\left(\sigma_{-1 l}\right)_{\text {exp }}$, $\left(\sigma_{-1}\right)_{\exp },\left(\tau_{-1}\right)_{\text {exp }},\left(\sigma_{0 l}\right)_{\text {exp }},\left(\sigma_{0}\right)_{\text {exp }}$, and $\left(\tau_{0}\right)_{\exp }$ denote the experimental data; $\sigma_{-1 l}, \sigma_{-1}, \tau_{-1}, \sigma_{0 l}, \sigma_{0}$, and $\tau_{0}$ denote the estimated fatigue limits deduced from the respective Eqs. (21)-(26); and "\%err" represents the relative errors of the estimated fatigue limit. For the purpose of evaluating the fatigue limits of materials, it is conceivable that Eqs. (21)-(26) can give reasonably good estimates. Because our present method provides an effective means to estimate the sum $\sigma_{\mathrm{E}, \mathrm{y}}+\sigma_{\mathrm{E}, \mathrm{b}}$, it would also be useful for estimating the fatigue limits for the cases when facilities for standard fatigue tests are not conveniently available. At last, we need to point out that the empirical Eqs. (21)-(26) are suggested for middle or low strength steels 
TABLE IV. Experimental and evaluated fatigue limits for some steels (unit in MPa, stress cycling number $N=10^{7}$ ).

\begin{tabular}{|c|c|c|c|c|c|c|c|c|c|c|c|}
\hline Type of steel & $\sigma_{\mathrm{E}, \mathrm{y}}$ & $\sigma_{\mathrm{E}, \mathrm{b}}$ & $\left(\sigma_{-1 I}\right)_{\exp }$ & & $\sigma_{-1 I}$ & $\%$ err $\sigma_{-1 I}$ & $\left(\sigma_{-1}\right)_{\exp }$ & $\sigma_{-1}$ & \multicolumn{2}{|c|}{$\%$ err $\sigma_{-1}$} & $\left(\tau_{-1}\right)_{\exp }$ \\
\hline \multicolumn{12}{|l|}{ Carbon steel } \\
\hline St. 34 & 220 & 340 & 120 & & 129 & 6.8 & 160 & 151 & & & 90 \\
\hline St. 38 & 240 & 380 & 130 & & 143 & 8.8 & 180 & 167 & & & 100 \\
\hline St. 42 & 260 & 420 & 140 & & 156 & 10.5 & 200 & 184 & & & 120 \\
\hline St. 50 & 300 & 500 & 180 & & 184 & 2.2 & 240 & 216 & & & 140 \\
\hline St. $52-3$ & 360 & 520 & 200 & & 202 & 1.2 & 280 & 238 & & & 160 \\
\hline St. 60 & 340 & 600 & 200 & & 216 & 7.5 & 280 & 254 & & & 160 \\
\hline St. 70 & 370 & 700 & 230 & & 246 & 6.5 & 320 & 289 & & & 190 \\
\hline \multicolumn{12}{|l|}{ Heat-treated steel } \\
\hline C 25 & 310 & 500 & 210 & & 186 & -12.7 & 260 & 219 & & & 150 \\
\hline C 35 & 370 & 600 & 230 & & 223 & -3.1 & 290 & 262 & & & 170 \\
\hline C 45 & 400 & 650 & 250 & & 242 & -3.5 & 320 & 284 & & & 180 \\
\hline C 60 & 490 & 750 & 290 & & 285 & -1.7 & 360 & 335 & & & 210 \\
\hline $40 \mathrm{Mn} 4$ & 550 & 800 & 310 & & 311 & 0.2 & 390 & 365 & & & 230 \\
\hline 37MnSi5 & 650 & 900 & 350 & & 357 & 1.8 & 440 & 419 & & & 260 \\
\hline $42 \mathrm{MnV7}$ & 800 & 1000 & 380 & & 414 & 8.2 & 480 & 486 & & & 290 \\
\hline $40 \mathrm{Cr} 4$ & 650 & 900 & 360 & & 357 & -1.0 & 440 & 419 & & & 260 \\
\hline $50 \mathrm{CrV} 4$ & 900 & 1100 & 400 & & 460 & 13.0 & 510 & 540 & & & 310 \\
\hline $25 \mathrm{CrMo} 4$ & 550 & 800 & 310 & & 311 & 0.2 & 380 & 365 & & & 210 \\
\hline 34CrMo4 & 650 & 900 & 360 & & 357 & -1.0 & 440 & 419 & & & 250 \\
\hline $42 \mathrm{CrMo} 4$ & 800 & 1000 & 380 & & 414 & 8.2 & 480 & 486 & & & 290 \\
\hline $50 \mathrm{CrMo} 4$ & 900 & 1100 & 430 & & 460 & 6.5 & 510 & 540 & & & 310 \\
\hline 30CrMoV9 & 1050 & 1250 & 450 & & 529 & 14.9 & 560 & 621 & & & 340 \\
\hline 36CrNiMo4 & 800 & 1000 & 390 & & 414 & 5.8 & 480 & 486 & & & 280 \\
\hline Type of steel & $\tau_{-1}$ & $\%$ err $\tau_{-1}$ & $\left(\sigma_{0 I}\right)_{\exp }$ & $\sigma_{0 I}$ & $\%$ err $\sigma_{0 I}$ & $\left(\sigma_{0}\right)_{\exp }$ & $\sigma_{0}$ & $\%$ err $\sigma_{0}$ & $\left(\tau_{0}\right)_{\exp }$ & $\tau_{0}$ & $\%$ err $\tau_{0}$ \\
\hline \multicolumn{12}{|l|}{ Carbon steel } \\
\hline St. 34 & 83 & -8.2 & 190 & 183 & -3.9 & 240 & 201 & -19.3 & 130 & 125 & -4.2 \\
\hline St. 38 & 92 & -8.6 & 210 & 202 & -3.7 & 260 & 223 & -16.8 & 150 & 138 & -8.6 \\
\hline St. 42 & 101 & -18.8 & 240 & 222 & -8.1 & 300 & 244 & -22.9 & 160 & 151 & -5.6 \\
\hline ST. 50 & 119 & -17.8 & 300 & 261 & -14.8 & 370 & 287 & -28.8 & 190 & 178 & -6.6 \\
\hline St. $52-3$ & 131 & -22.4 & 330 & 287 & -14.8 & 410 & 316 & -29.7 & 220 & 196 & -12.2 \\
\hline St. 60 & 140 & -14.6 & 340 & 307 & -10.7 & 430 & 338 & -27.4 & 220 & 209 & -5.1 \\
\hline St. 70 & 159 & -19.6 & 370 & 349 & -5.9 & 490 & 384 & -27.5 & 260 & 238 & -9.1 \\
\hline \multicolumn{12}{|l|}{ Heat-treated steel } \\
\hline C 25 & 120 & -24.7 & 310 & 265 & -17.2 & 390 & 291 & -34.1 & 200 & 180 & -10.8 \\
\hline C 35 & 144 & -18.0 & 370 & 317 & -16.8 & 440 & 348 & -26.3 & 250 & 216 & -15.7 \\
\hline C 45 & 156 & -15.4 & 400 & 343 & -16.6 & 490 & 377 & -30.0 & 270 & 234 & -15.4 \\
\hline C 60 & 184 & -14.0 & 480 & 405 & -18.5 & 550 & 445 & -23.5 & 310 & 276 & -12.2 \\
\hline $40 \mathrm{Mn} 4$ & 200 & -14.7 & 510 & 441 & -15.7 & 590 & 485 & -21.7 & 280 & 301 & 6.9 \\
\hline $37 \mathrm{MnSi} 5$ & 230 & -13.0 & 580 & 506 & -14.6 & 680 & 557 & -22.2 & 410 & 345 & -18.8 \\
\hline $42 \mathrm{MnV} 7$ & 267 & -8.5 & 640 & 588 & -8.9 & 740 & 646 & -14.5 & 460 & 401 & -14.7 \\
\hline $40 \mathrm{Cr} 4$ & 230 & -13.0 & 600 & 506 & -18.5 & 670 & 557 & -20.4 & 400 & 345 & -15.9 \\
\hline $50 \mathrm{CrV} 4$ & 297 & -4.4 & 680 & 653 & -4.1 & 800 & 718 & -11.4 & 480 & 446 & -7.7 \\
\hline $25 \mathrm{CrMo} 4$ & 200 & -4.8 & 520 & 441 & -17.9 & 590 & 485 & -21.7 & 270 & 301 & 10.2 \\
\hline 34CrMo4 & 230 & -8.6 & 590 & 506 & -16.5 & 680 & 557 & -22.2 & 390 & 345 & -13.0 \\
\hline $42 \mathrm{CrMo} 4$ & 267 & -8.5 & 640 & 588 & -8.9 & 740 & 646 & -14.5 & 450 & 401 & -12.2 \\
\hline $50 \mathrm{CrMo} 4$ & 297 & -4.4 & 720 & 653 & -10.2 & 790 & 718 & -10.0 & 480 & 446 & -7.7 \\
\hline 30CrMoV9 & 342 & 0.5 & 760 & 751 & -1.2 & 880 & 826 & -6.5 & 480 & 512 & 6.3 \\
\hline 36CrNiMo4 & 267 & -4.8 & 650 & 588 & -10.6 & 730 & 646 & -12.9 & 450 & 401 & -12.2 \\
\hline
\end{tabular}

only. If it is applied to high strength steels, the fatigue limits may be overestimated.

\section{CONCLUSIONS}

In this study, the existence of a functional dependence of $\left(\sigma_{\mathrm{E}, \mathrm{y}}+\sigma_{\mathrm{E}, \mathrm{b}}\right) /$ indentation hardness on reversible elastic work to total work ratio was established by using dimensional and finite element analyses. The published experimental data of uniaxial tests and indentation tests made on aluminum alloys 6061-T6511 and 7075-T651 support the effectiveness of the theory. The establishment of the relationship gives a physical explanation to the Oliver $\&$ Pharr hardness, which may be very different 
from the real hardness in some situations. One important application of the functional relationship is for the determination the sum of the yield strength and tensile strength based on the results of an indentation test. The sum of the two strengths obtained was considered to be more suitable for reflecting the strength level of different materials since it is considered to be more physically meaningful than the indentation hardness. Another important application of the functional relationship is to estimate the fatigue limits of some structural steel by using the data of indentation test.

\section{ACKNOWLEDGMENT}

This work was supported by the National Natural Science Foundation of China (Grant Nos. 10432050, 10372103) and an internal grant (account code: G-T841) funded by the Hong Kong Polytechnic University.

\section{REFERENCES}

1. D. Tabor: The Hardness of Metals (Oxford, London, UK, 2000), pp.104-106.

2. Y-T. Cheng and C-M. Cheng: Scaling approach to conical indentation in elastic-plastic solids with work hardening. J. Appl. Phys. 84, 1284 (1998).

3. M. Dao, N. Chollacoop, K.J. Van Vliet, T.A. Venkatesh, and S. Suresh: Computational modeling of the forward and reverse problems in instrumented sharp indentation. Acta Mater. 49, 3899 (2001).

4. A.E. Giannakopoulos and S. Suresh: Determiniation of elastoplastic properties by instrumented sharp indentation. Scripta Mater. 40, 1191 (1999).

5. K. Zeng and C.H. Chiu: An analysis of load-penetration curves from instrumented indentation. Acta Mater. 49, 3539 (2001).

6. Y-T. Cheng and C-M. Cheng: Can stress-strain relationships be obtained from indentation curves using conical and pyramidal indenters? J. Mater. Res. 14, 3493 (1999).

7. T.W. Capehart and Y-T. Cheng: Determining constitutive models from conical indentation: Sensitivity analysis. J. Mater. Res. 18, 827 (2003).

8. K.K. Tho, S. Swaddiwudhipong, Z.S. Liu, K. Zeng, and J. Hua: Uniqueness of reverse analysis from conical indentation tests. J. Mater. Res. 19, 2498 (2004).

9. J.L. Bucaille, S. Stauss, E. Felder, and J. Michler: Determination of plastic properties of metals by instrumented indentation using different sharp indenters. Acta Mater. 51, 1663 (2003).

10. Y. Cao, X. Qian, J. Lu, and Z. Yao: An energy-based method to extract plastic properties of metal materials from conical indentation tests. J. Mater. Res. 20, 1194 (2005).

11. W.C. Oliver and G.M. Pharr: An improved technique for determining hardness and elastic modulus using load and displacement sensing indentation experiments. J. Mater. Res. 7, 1564 (1992).

12. G.M. Pharr, W.C. Oliver, and F.R. Brotzen: On the generality of the relationship among contact stiffness, contact area, and elastic modulus during indentation. J. Mater. Res. 7, 613 (1992).

13. W.C. Oliver and G.M. Pharr: Measurement of hardness and elastic modulus by instrumented indentation: Advances in understanding and refinements to methodology. J. Mater. Res. 19, 3 (2004).

14. ABAQUS: Version 6.2 (Hibbitt, Karlsson \& Sorensen, Inc., Pawtucket, RI, 2001).
15. D. Ma, T. Zhang, and C.W. Ong: Evaluation of effectiveness of representative methods for determining Young's modulus and hardness from instrumented indentation data. J. Mater. Res. 21, 225 (2006).

16. D. Ma, C.W. Ong, and S.F. Wong: New relationship between Young's modulus and nonideally sharp indentation parameters. J. Mater. Res. 19, 2144 (2004).

17. D. Ma, C.W. Ong, J. Lu, and J. He: Methodology for the evaluation of yield strength and hardening behavior of metallic materials by indentation with spherical tip. J. Appl. Phys. 94, 288 (2003).

18. Y. Song: Design, Selection and Prediction of Metallic Materials (Mechanical Industry Press, Beijing, China, 1998), p. 443.

19. H. Xu: Design of Fatigue Strength (Mechanical Industry Press, Beijing, China, 1981), p. 45 (in Chinese).

20. M. Li, O. Buxbaum, and H. Lowak: Structure Design Against Fatigue (Mechanical Industry Press, Beijing, China, 1987), p. 31 (in Chinese).

\section{APPENDIX A: FUNCTIONAL DEPENDENCE OF $\sigma_{E, y}$ ON FUNDAMENTAL MATERIAL PROPERTIES}

In a tensile test, when the load is increased from zero to a certain value, the transverse cross-sectional radius and area vary from the unstressed values $r_{\mathrm{o}}$ and $A_{\mathrm{o}}=\pi r_{\mathrm{o}}^{2}$ to the instantaneous values $r$ and $A=\pi r^{2}$. At this moment, the engineering stress is

$$
\sigma_{\mathrm{E}}=F / A_{\mathrm{o}}=(F / A)\left(A / A_{\mathrm{o}}\right)=\sigma_{\mathrm{T}}\left(A / A_{\mathrm{o}}\right)=\sigma_{\mathrm{T}}\left(r / r_{\mathrm{o}}\right)^{2}
$$

The $r / r_{\mathrm{o}}$ is achieved from the definition of true radial strain

$$
\epsilon_{\mathrm{T}, \mathrm{r}}=\int_{r_{\mathrm{o}}}^{r} \mathrm{~d} r / r=\ln \left(r / r_{\mathrm{o}}\right),
$$

which is also equal to $-v \epsilon_{\mathrm{T}}$ in the elastic regime, such that

$$
\begin{gathered}
r / r_{\mathrm{o}}=\exp \left(-v \epsilon_{\mathrm{T}}\right) \quad \text { and }, \\
A / A_{\mathrm{o}}=\left(r / r_{\mathrm{o}}\right)^{2}=\exp \left(-2 \nu \epsilon_{\mathrm{T}}\right) .
\end{gathered}
$$

Substituting Eq. (A3) into Eq. (A1), one obtains:

$$
\begin{gathered}
\sigma_{\mathrm{E}}=\sigma_{\mathrm{T}} / \exp \left(2 \nu \epsilon_{\mathrm{T}}\right), \\
\text { and } \sigma_{\mathrm{E}, \mathrm{y}}=\sigma_{\mathrm{T}, \mathrm{y}} / \exp \left(2 \nu \epsilon_{\mathrm{T}, \mathrm{y}}\right)=\sigma_{\mathrm{T}, \mathrm{y}} / \exp \left(2 \nu \sigma_{\mathrm{T}, \mathrm{y}} / E\right)
\end{gathered}
$$

The latter is Eq. (2) in the text.

\section{APPENDIX B: FUNCTIONAL DEPENDENCE OF $\epsilon_{T, b}$ AND $\sigma_{E, b}$ ON FUNDAMENTAL MATERIAL PROPERTIES}

For an uniaxial stress-strain relation, the true strain $\epsilon_{\mathrm{T}}$ in the plastic regime should consist of two parts, i.e. 
elastic strain $\epsilon_{\mathrm{T}}^{\mathrm{e}}=\sigma_{\mathrm{T}} / E$ and plastic strain $\epsilon_{\mathrm{T}}^{\mathrm{p}}=\epsilon_{\mathrm{T}}-$ $\epsilon_{\mathrm{T}}^{\mathrm{e}}=\epsilon_{\mathrm{T}}-\sigma_{\mathrm{T}} / E$. According to the theory of elasticity, the radial strain associated with the former is $\epsilon_{\mathrm{T}, \mathrm{r}}^{\mathrm{e}}=-\nu \sigma_{\mathrm{T}} / E$. From the constant-volume condition for plastic deformation, the radial strain associated with the plastic strain $\epsilon_{\mathrm{T}}^{\mathrm{p}}$ is $\epsilon_{\mathrm{T}, \mathrm{r}}^{\mathrm{p}}=-0.5 \epsilon_{\mathrm{T}}^{\mathrm{p}}=-0.5\left(\epsilon_{\mathrm{T}}-\sigma_{\mathrm{T}} / E\right)$. Summarizing these results, the overall true radial strain $\epsilon_{\mathrm{T}, \mathrm{r}}$ is expressed as:

$$
\begin{aligned}
\epsilon_{\mathrm{T}, \mathrm{r}} & =\epsilon_{\mathrm{T}, \mathrm{r}}^{\mathrm{e}}+\epsilon_{\mathrm{T}, \mathrm{r}}^{\mathrm{p}} \\
& =-\left[\nu \sigma_{\mathrm{T}} / E+0.5\left(\epsilon_{\mathrm{T}}-\sigma_{\mathrm{T}} / E\right)\right] \\
& =-\left[0.5 \epsilon_{\mathrm{T}}+(\nu-0.5) \sigma_{\mathrm{T}} / E\right] .
\end{aligned}
$$

After replacing $\sigma_{\mathrm{T}}$ with $\sigma_{\mathrm{T}, \mathrm{y}}\left(\epsilon_{\mathrm{T}} / \epsilon_{\mathrm{T}, \mathrm{y}}\right)^{n}$, Eq. (A6) becomes:

$$
\epsilon_{\mathrm{T}, \mathrm{r}}=-\left[0.5 \epsilon_{\mathrm{T}}+(\nu-0.5) \epsilon_{\mathrm{T}, \mathrm{y}}^{1-n} \epsilon_{\mathrm{T}}^{n}\right] .
$$

When the engineering stress reaches the maximum value, the increase in load for further elongating the specimen is compensated with the reduction in cross-sectional area, namely:

$$
\begin{aligned}
\mathrm{d} F & =\mathrm{d}\left(\sigma_{\mathrm{T}} A\right)=\sigma_{\mathrm{T}} \mathrm{d} A+A \mathrm{~d} \sigma_{\mathrm{T}}=0, \\
-\mathrm{d} A / A & =\mathrm{d} \sigma_{\mathrm{T}} / \sigma_{\mathrm{T}} .
\end{aligned}
$$

The two sides of Eq. (A9) are $-\mathrm{d} A / A=-2 \mathrm{~d} r / r=-2$ $\mathrm{d} \epsilon_{\mathrm{T}, \mathrm{r}}$ and $\mathrm{d} \sigma_{\mathrm{T}} / \sigma_{\mathrm{T}}=\mathrm{d}\left[\sigma_{\mathrm{T}, \mathrm{y}}\left(\epsilon_{\mathrm{T}} / \epsilon_{\mathrm{T}, \mathrm{y}}\right)^{n}\right] /\left[\sigma_{\mathrm{T}, \mathrm{y}}\left(\epsilon_{\mathrm{T}} / \epsilon_{\mathrm{T}, \mathrm{y}}\right)^{n}\right]=$ $n \mathrm{~d} \epsilon_{\mathrm{T}} / \epsilon_{\mathrm{T}}$, respectively, so that:

$$
-2 \mathrm{~d} \epsilon_{\mathrm{T}, \mathrm{r}}=n \mathrm{~d} \epsilon_{\mathrm{T}} / \epsilon_{\mathrm{T}}
$$

By substituting Eq. (A7) into Eq. (A10), at $\epsilon_{\mathrm{T}}=\epsilon_{\mathrm{T}, \mathrm{b}}$, Eq. (A10) is transformed to become Eq. (3):

$$
\epsilon_{\mathrm{T}, \mathrm{b}}=n\left[1+(1-2 v) \epsilon_{\mathrm{T}, \mathrm{y}}^{1-n} \epsilon_{\mathrm{T}, \mathrm{b}}^{1-n}\right] .
$$

From Eq. (A7), when $\epsilon_{\mathrm{T}, \mathrm{b}}>\epsilon_{\mathrm{T}, \mathrm{y}}$, the radial strain $\epsilon_{\mathrm{T}, \mathrm{r}}$ and engineering stress $\sigma_{\mathrm{E}, \mathrm{b}}$ at $\epsilon_{\mathrm{T}}=\epsilon_{\mathrm{T}, \mathrm{b}}$ can be determined as:

$$
\begin{aligned}
\left.\epsilon_{\mathrm{T}, r}\right|_{\epsilon_{\mathrm{T}}=\epsilon_{\mathrm{T}, \mathrm{b}}} & =-\left.\left[0.5 \epsilon_{\mathrm{T}}+(v-0.5) \epsilon_{\mathrm{T}, \mathrm{y}}^{1-n} \epsilon_{\mathrm{T}}^{n}\right]\right|_{\epsilon_{\mathrm{T}}=\epsilon_{\mathrm{T}, \mathrm{b}}} \\
& =-\left[0.5 \epsilon_{\mathrm{T}, \mathrm{b}}+(v-0.5) \epsilon_{\mathrm{T}, \mathrm{y}}^{1-n} \epsilon_{\mathrm{T}, \mathrm{b}}^{n}\right],
\end{aligned}
$$

and $\quad \sigma_{\mathrm{E}, \mathrm{b}}=\frac{\left.F\right|_{\epsilon_{\mathrm{T}}=\epsilon_{\mathrm{T}, \mathrm{b}}}}{A_{\mathrm{o}}}=\frac{\left.F\right|_{\epsilon_{\mathrm{T}}=\epsilon_{\mathrm{T}, \mathrm{b}}}}{\left.A\right|_{\epsilon_{\mathrm{T}}=\epsilon_{\mathrm{T}, \mathrm{b}}}} \frac{\left.A\right|_{\epsilon_{\mathrm{T}}=\epsilon_{\mathrm{T}, \mathrm{b}}}}{A_{\mathrm{o}}}$

$$
\begin{aligned}
& =\left.\left.\sigma_{\mathrm{T}}\right|_{\epsilon_{\mathrm{T}}=\epsilon_{\mathrm{T}, \mathrm{b}}}\left(\frac{r}{r_{\mathrm{o}}}\right)^{2}\right|_{\epsilon_{\mathrm{T}}=\epsilon_{\mathrm{T}, \mathrm{b}}} \\
& =\sigma_{\mathrm{T}, \mathrm{b}} \exp \left(\left.2 \epsilon_{\mathrm{T}, \mathrm{r}}\right|_{\epsilon_{\mathrm{T}}=\epsilon_{\mathrm{T}, \mathrm{b}}}\right) \\
& =\frac{\sigma_{\mathrm{T}, \mathrm{y}}\left(\epsilon_{\mathrm{T}, \mathrm{b}} / \epsilon_{\mathrm{T}, \mathrm{y}}\right)^{n}}{\exp \left[\epsilon_{\mathrm{T}, \mathrm{b}}+(2 v-1) \epsilon_{\mathrm{T}, \mathrm{y}}^{1-n} \epsilon_{\mathrm{T}, \mathrm{b}}^{n}\right]} .
\end{aligned}
$$

This is Eq. (4) in the text. 